\title{
A BASELINE STUDY ON MACROZOOBENTHOS ASSEMBLAGES IN PASIR ISLAND
}

\author{
Fiddy Semba Prasetiya*a,c, Yusuf Arief Nurrahman ${ }^{\text {, }}$, Sheila Zalessa ${ }^{a}$, \\ Sri Astuty ${ }^{\mathrm{a}}$, Indah Riyantini ${ }^{\mathrm{a}}$, Ibnu Faizal ${ }^{\mathrm{a}}$ \\ ${ }^{a}$ Department of Marine Science, Faculty of Fisheries and Marine Science, Universitas Padjadjaran \\ Jl. Raya Bandung-Sumedang KM 21 Jatinangor, Sumedang, West Java 45363 Indonesia \\ ${ }^{\mathrm{b}}$ Department of Marine Science, Faculty of Mathematic and Natural Science, Universitas Tanjungpura, \\ Prof. Dr. H. Hadari Nawawi Street 78124, West Kalimantan, Indonesia \\ ${ }^{c}$ Research Center of Biotechnology and Bioinformatics, Jl. Singaperbangsa No. 2, Bandung 40132, Indonesia \\ *Corresponding author : fiddy.semba.prasetiya@unpad.ac.id
}

\begin{abstract}
Biodiversity of macrozoobenthos in Pasir Island, Brebes, is under-explored. On the other hand, the baseline information regarding macrozoobenthos is essentially required for better future environmental management. This research aims to analyze macrozoobenthos community structure in the Pasir Island that has not been documented. Surveys were carried out in the rainy season. In this study, a total of 10 sampling locations were classified into two different groups that represent "control" and "disturbed" station. The main structural parameters of the macrozoobenthos identified at each station were specific richness $(\mathrm{S})$, abundance (number of individuals $\mathrm{m}^{-2}, \mathrm{~N}$ ) and the Pielou's index $(\mathrm{J})$. Additionally, the pairwise comparison between groups was conducted by using analysis of similarity (ANOSIM) and the similarity percentage (SIMPER) to obtain the description of community structure. A total of 1054 specimens were counted from the "control" and "disturbed" stations. These specimens were belonged to five animal classes, namely, Bivalvia, Gastropoda, Malacostraca, Cephalopoda and Echinoidea. ANOSIM and SIMPER analysis demonstrated that significant difference was found between "control" and "disturbed" stations with the percentage of dissimilarity value of $88.82 \%$. In addition, environmental variables such $\mathrm{pH}$, salinity and type of substrates contributed significantly to this difference. This result provides the insight regarding macrozoobenthos diversity and ecological information that may contribute to further conservation management in the Pasir Island, Indonesia.
\end{abstract}

Keywords : Pasir Island, macrozoobenthos, diversity, community structure

\section{INTRODUCTION}

Macrozoobenthos can be defined as the invertebrate bottom fauna living on, or in the bottom, which is retained on a sieve with a mesh size of $1 \mathrm{~mm}$ x $1 \mathrm{~mm} \mathrm{[1].} \mathrm{These}$ organisms can be mollusks, mainly bivalves, polychaetes or decapod crustaceans. The macr ozoobenthos play a significant role in the food web of aquatic ecosystem, which are the main connector between the primary producers and higher trophic levels [2]. They are the most important consumers of both the pelagic phytoplankton and benthic microphytobenthos, which are responsible for the larger part of the systems primary production. Sequentially, the macrozoobenthos provide rich feeding grounds for predatory fish and birds [1], [2].

Macrozoobenthos are also considered as one of the most useful bioindicators and biomonitors of aquatic health due to their inherent characteristics, including continuous exposure to prevailing water quality, longevity, abundance, diversity, large size and relative immobility [3], [4]. Therefore, their sensitivity to environment alteration makes them justifiably important to use in monitoring studies [2], [5], [6].

The sandy beaches of Pasir island is situated in the North Coast of Java Island in Brebes district. This area has been considered vulnerable to coastal erosion due to deforestation of mangrove forest. Previous report from the Department of Fisheries and Marine Affairs of Brebes (2015) recorded that the rate of coastal erosion was almost $30 \mathrm{~m}$ year-1 during the last 8 years. However, impact of this coastal erosion to the macrozoobenthos in this area has never been documented. Therefore, a preliminary survey concerning the impact of anthropogenic activities on this organism is required to provide a better coastal management in the near future. 
The present study aims to provide the baseline data on macrozoobenthos diversity in the Brebes District sandy beaches, and to investigate the distributional relationship between the macrozoobenthic communities and the environmental parameters in relation to the level of disturbances in the study site.

\section{MATERIALS AND METHODS}

\section{Study site and sampling procedures}

The sandy beaches of Pasir Island covers 10 ha of area including the replanted mangrove forest due to coastal erosion and excessive deforestation. Surveys were carried out in the rainy season on November 2017. In the present study, a total of 10 sampling locations were chosen where two different group categories were classified as "control" and "disturbed" sites (Table 1, Fig. 1). The "control" site was indicated by the minimum anthropogenic activities, while the "disturbed" site was chosen due to higher intensity of human activities and the presence of tourist port. Macrozoobenthos at each station was taken during the low tide at approximately $10 \mathrm{~m}$ from the low water mark. Samples were taken by using hand corer (Wildco 96" SS Kit) at quadrat $(20 \mathrm{~cm} \times 20$ $\mathrm{cm})$ thrown arbitrarily. Furthermore, samples were sieved in the field using a set of siever of mesh size 4,2 and $0.5 \mathrm{~mm}$. The retained organisms were then stored in $10 \%$ formalin for detailed examination in the laboratory. Prior to identification, the samples were stained with Rose Bengal in order to enhance their visibility. Morphological identification of macrozoobenthos was conducted to the species level by using the standard macrozoobenthos identification books from [7] and [8]. The nomenclature writing of identified organisms was arranged following the database from the international World Register of Marine Species (WoRMS:

http://www.marinespecies.org/index.php). 
Table 1. Characteristics of sampling stations

\begin{tabular}{|c|c|c|c|}
\hline Station & Latitude & Longitude & Category \\
\hline 1 & $6^{\circ} 47^{\prime} 47.81 " \mathrm{~S}$ & $108^{\circ} 59^{\prime} 26.41 " \mathrm{E}$ & Disturbed \\
\hline 2 & $6^{\circ} 47^{\prime} 46.45^{\prime \prime S}$ & $108^{\circ} 59^{\prime} 27.86 " \mathrm{E}$ & Disturbed \\
\hline 3 & $6^{\circ} 47^{\prime} 44.36^{\prime \prime S}$ & $108^{\circ} 59^{\prime} 31.86 " \mathrm{E}$ & Disturbed \\
\hline 4 & $6^{\circ} 47^{\prime} 43.31 " \mathrm{~S}$ & $108^{\circ} 59^{\prime} 33.52^{\prime \prime} \mathrm{E}$ & Disturbed \\
\hline 5 & $6^{\circ} 47^{\prime} 42.22^{\prime \prime} \mathrm{S}$ & $108^{\circ} 59^{\prime} 34.96 " \mathrm{E}$ & Disturbed \\
\hline 6 & $6^{\circ} 47^{\prime} 40.32^{\prime \prime S}$ & $108^{\circ} 59^{\prime} 36.39 " \mathrm{E}$ & Control \\
\hline 7 & $6^{\circ} 47^{\prime} 37.58 " \mathrm{~S}$ & $108^{\circ} 59^{\prime} 39.38^{\prime \prime} \mathrm{E}$ & Control \\
\hline 8 & $6^{\circ} 47^{\prime} 39.34 " \mathrm{~S}$ & $108^{\circ} 59^{\prime} 40.62 " \mathrm{E}$ & Control \\
\hline 9 & $6^{\circ} 47^{\prime} 37.15^{\prime \prime S}$ & $108^{\circ} 59^{\prime} 43.07 " \mathrm{E}$ & Control \\
\hline 10 & $6^{\circ} 47 ' 35.34 " \mathrm{~S}$ & $108^{\circ} 59^{\prime} 44.10^{\prime \prime} \mathrm{E}$ & Control \\
\hline
\end{tabular}

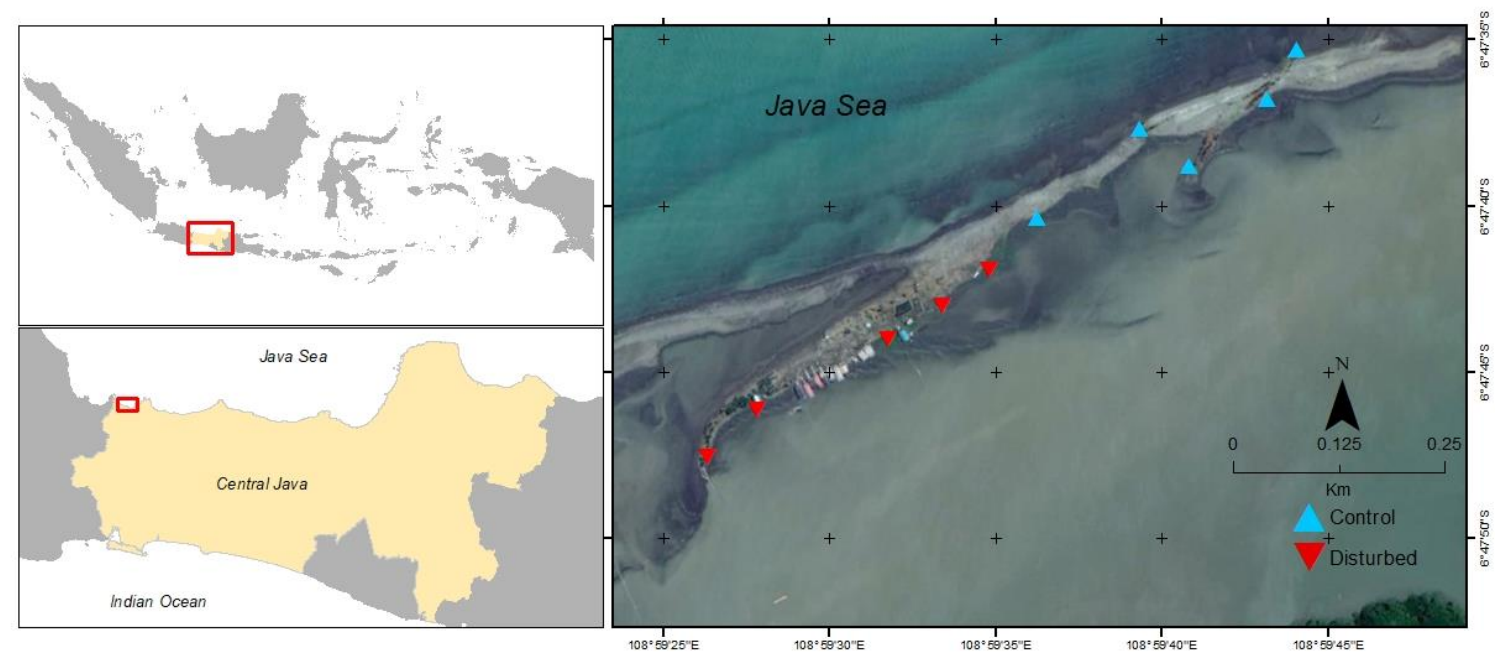

Figure 1. Map of study area with location of sampling sites in the sandy beach of Pasir Island

\section{Environmental parameters}

Measurement on environmental parameters was carried out in 10 stations as previously described in the section "study site and laboratory procedures" and Table 1 . Salinity was measured in situ by a refractometer (type ATAGO Master-S/Mill 2491), $\mathrm{pH}$ by a $\mathrm{pH}$-meter (type Lutron $\mathrm{PH}-$ 208), Water Temperature and Dissolve Oxygen by a DO Meter (type Lutron DO5519). Sediment samples were analyzed in the laboratory. Sediment grain size was measured by using sieve-shaker (type AG-515, 8"Sieve) and the grain size composition was identified following the protocol from [9]. Furthermore, Total organic carbon (TOC) from sediment samples was analyzed according to [10].

\section{Data analysis}

The community structure of macrozoobenthos was assessed by calculating the main structural parameters at each station such as, specific richness $\mathrm{S}$ (total species), abundance $\mathrm{N}$ (total individuals), the Pielou's evenness index J' [11] and the reciprocal of the proportional abundance of the most common species $\mathrm{N}_{\mathrm{inf}}$ [12]. These parameters were calculated using the PRIMER v6 package.

Assumptions of analysis of variance (ANOVA) were examined using box and normal probability plots. Homogeneity of variances was analyzed using Levene's test. The parametric analyses of variance (ANOVA) was used to test for significant differences in the densities and diversities of the different sites using GraphPad PRISM 5 for MacOS software.

The non-parametric procedures multidimensional scaling (MDS) twodimensional plot and one-way analysis of similarity (ANOSIM) were used to compare 
sample similarity based on species composition. Per sample, data were standardized to relative abundance data and square root transformed prior to analysis. The MDS diagram was produced based on BrayCurtis similarities between samples, calculated using the PRIMER v6 software package.

The environmental parameters were analyzed concomitantly with density and diversity of macrozoobenthos data by using Canonical Correspondence Analysis (CCA) as described in Prasetiya (2010) using PRIMER v6 software package.

\section{RESULTS AND DISCUSSION}

In this study, a total of 1054 specimens were counted from the two different stations ("control" and "disturbed"). The collected specimens were belonged to five animal classes, namely, Bivalvia, Gastropoda, Malacostraca, Cephalopoda and Echinoidea. Among these classes, a total of 54 species were successfully identified, whereas two specimens were not yet identified (named as "unidentified gastropod"). In terms of classes representation, Bivalvia constituted the highest relative density $(62 \%)$ and then followed by Gastropoda (35\%) (Fig.2). The ANOVA found that the density of Bivalvia was significantly lower in "control" station than in "disturbed" station $(\mathrm{p}<0.05)$. In contrast, the density of Gastropoda in "control" station was significantly higher than in "disturbed" station $\left(274\right.$ vs 93 ind $\left.\mathrm{m}^{-2}, \mathrm{p}<0.05\right)$.

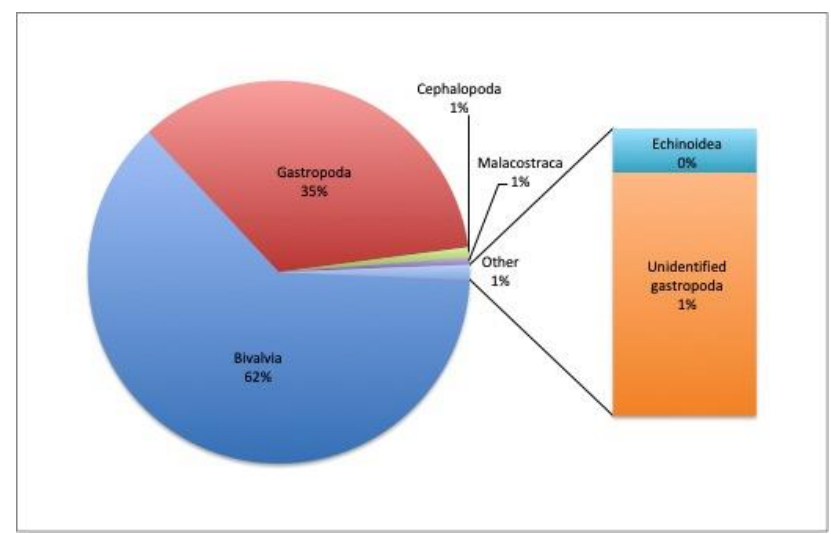

Figure 2. Relative density of macrozoobenthos in all sampling stations

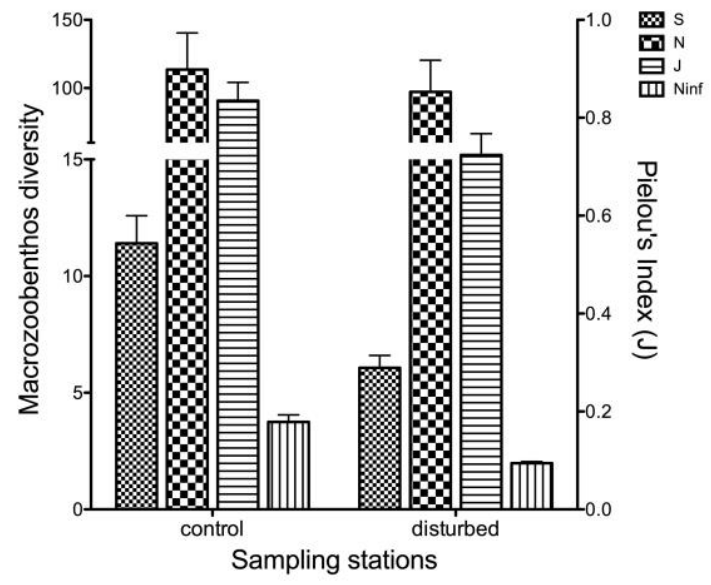

Figure 3. Macrozoobenthos diversity at two different sampling stations

The gastropods are considered to be sensitive animals that can move to avoid environmental stressors [5]. The non- parametric procedures multidimensional scaling (MDS) two-dimensional plots were used to compare sample similarity based on 
species composition. The Bray Curtis similarity with square-root transformation from two different sites ("control" and "disturbed") was calculated and showed on the figure 4. The MDS graph at species level showed that all of the two sites were relativey clustered separately from each other (Fig. 4). Pairwise comparison of the site groups with one-way analysis of similarity (ANOSIM) was significant between "control" and "disturbed" groups $(p=0.001)$, where the average dissimilarity between the two stations was $88.82 \%$. Additionally, the similarity of percentage-species contribution (SIMPER) analysis showed that Anadara sp. (10.22\%), Nereis sp. (5.71\%), Tellina sp. (5.20\%) and Turbo argyrostomus (4.71\%) explained the dissimilarity of species composition between "control" and "disturbed" stations. Similarity in species composition in "control" station was mainly due to Littorina scabra and Anadara sp. with the contribution of 12.03 and $11.43 \%$, respectively. In contrast, the similarity of species composition in the "disturbed" station, was mainly explained by Anadara sp. (40.94\%), Cerithidea obtusa (13.92\%) and Turbo argyrostomus (10.08\%).

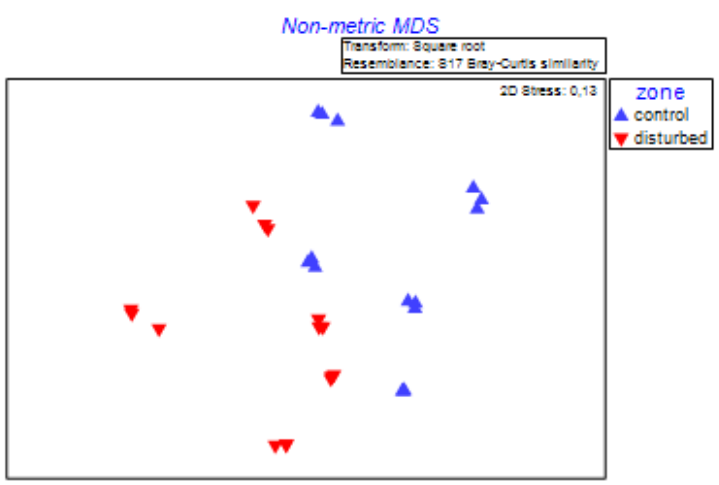

Figure 4. Community structure of macrozoobenthos at two different sampling sites in mangrove habitats. The nMDS two-dimensional ordination plot was constructed based on the Square root transformation of Bray-Curtis similarity with stress value indicated

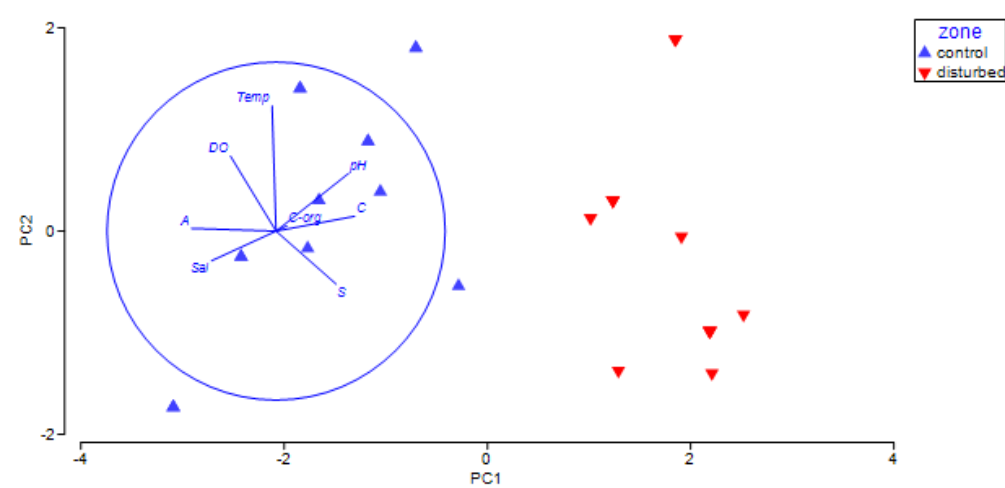

Figure 5. Canonical Correspondence Analysis (CCA) ordination plot of macrozoobenthos relative abundances and environmental variables. The arrows represents environmental variables (temperature, dissolved oxygen, $\mathrm{pH}$, salinity, total organic carbon, percentage of silt, ash and clay, represented by Temp, $\mathrm{DO}, \mathrm{pH}, \mathrm{Sal}, \mathrm{C}-\mathrm{org}, \mathrm{C}, \mathrm{A}$ and C, respectively)

Environmental parameters are important in structuring biota communities in an ecosystem. In this case, the physical, chemical and biological nature of the waters is very influential on the distribution of macrozoobenthos [13]. Several physical parameters such as depth, current speed, turbidity, and type of substrate as well as water temperature may directly affect macrozoobenthos. On the other hand, the chemical variables that directly influence on macrozoobenthos are the degree of acidity, salinity and dissolved oxygen content [5], [12], [13].

In this study, CCA diagram showed that salinity, $\mathrm{pH}$ and type of substrate significantly 
contribute to the difference of macrozoobenthos distribution between "control" and "disturbed" stations. In this study, salinity contribute to $11.45 \%$ dissimilarity between "control" and "disturbed" stations. Indeed, salinity can affect the distribution of macrozoobenthos both horizontally and vertically. In the present study, salinity in "control" sites ranged from 20 to $34 \%$. On the other hand, the "disturbed" sites had wider range of salinity, which is from 22 to $25 \%$. The ideal range of salinity for macrobenthos fauna is range from 15 to $35 \%$ [4], [5]. Therefore, the range of salinity observed in this study was still comparable to other studies.

CCA showed that acidity (pH) corresponds to $13.31 \%$ of dissimilarity between "control" and "disturbed" stations (Fig. 5). Indeed, $\mathrm{pH}$ is a limiting factor for aquatic organisms. In the present study, $\mathrm{pH}$ in the "disturbed" sites ranged from 6.35 to 7.01 . This range is relatively lower than that of "control" sites (7.5 to 8). To our knowledge, most aquatic organisms are sensitive to changes in $\mathrm{pH}$ and prefer a $\mathrm{pH}$ range of around $7-8.5$. Lower $\mathrm{pH}$ may indicate the lack of oxygen due to microbial activity in degradation process, for instance the organic pollutant. This could be one of the explanations why the abundance of macrozoobenthos in "disturbed" sites was significantly lower than the abundance in the "control" sites. A very acidic $\mathrm{pH}$ may affect the survival of macrozoobenthos due to disruption of metabolism and respiration [14], [15].

In the present study, CCA showed that type of substrate contribute to approximately $46.39 \%$ of dissimilarity between "control" and "disturbed" stations. Indeed, substrate is one of the most essential parameters for macrozoobenthos that live in the waters. In this study, the type of substrates on both groups of sites are classified into silt, clay and ash. The proportion of silt substrate in "control" site was higher than in "disturbed" site where approximately $15.42 \%$ of silt type of substrate contributed to the dissimilarity between those two sites. In general, silt base substrates are more favored by benthos [1].

To our knowledge, the biological parameters such as competition, predators and the level of primary productivity can also affect the macrozoobenthos community. These biological factors can either stand-alone or interact with each other, which can shape the community of macrozoobenthos in coastal environment [16].

\section{CONCLUSION}

The present study explained that the community structure of macrozoobenthos between "control" and "disturbed" stations is varying, where the species richness (S) and Pielou's Index $(\mathrm{J})$ in the "control" site is generaly higher than the "disturbed" sites. Gastropoda and Bivalvia are the most important discriminators between these two sites. This study provides an insight regarding macrozoobenthos diversity and ecological information that may be used for further conservation management in the Pasir Island Brebes, Indonesia.

\section{ACKNOWLEDGEMENT}

The authors would like to thank the fellow students of Faculty of Fisheries and Marine Science (FPIK) Universitas Padjadjaran for the technical assistance during the sampling campaign. The authors also wish to thank to the Directorate of Research and Community Service (DRPM) Universitas Padjadjaran for supporting this study.

\section{REFERENCES}

[1] S. van der Graaf, J. de Vlas, M. Herlyn, J. Voss, H. Karin, and J. Drent, "Macrozoobenthos. Thematic Report No. 10. Wadden Sea Ecosystem No. 25. In: Marencic, H. \& Vlas, J. de (Eds), 2009. Quality Status Report 2009. WaddenSea Ecosystem No. 25. Common Wadden Sea Secretariat, Trilateral Monitoring and Assessment Group, Wilhelmshav," vol. 39, no. 1, pp. 15-27, 2009.

[2] R. C. Nalesso, J.-C. Joyeux, C. O. Quintana, E. Torezani, and A. C. P. Otegui, "Soft-Bottom macrobenthic communities of the Vitória Bay estuarine system, South-eastern Brazil," Brazilian J. Oceanogr., vol. 53, no. 1-2, pp. 23-38, 
2005.

[3] A. Borja, J. Franco, and V. Pérez, "A marine Biotic Index to establish the ecological quality of soft-bottom benthos within European estuarine and coastal environments," Mar. Pollut. Bull., vol. 40, no. 12, pp. 1100-1114, 2000.

[4] N. Zabbey and H. Uyi, "Community responses of intertidal soft-bottom macrozoobenthos to oil pollution in a tropical mangrove ecosystem, Niger Delta , Nigeria," Mar. Pollut. Bull., vol. 82, no. 1-2, pp. 167-174, 2014.

[5] I. Khedhri, A. Afli, and L. Aleya, "Structuring factors of the spatiotemporal variability of macrozoobenthos assemblages in a southern Mediterranean lagoon: How useful for bioindication is a multi-biotic indices approach?," Mar. Pollut. Bull., vol. 114, no. 1, pp. 515-527, 2017.

[6] N. Zabbey and A. I. Hart, "African Journal of Aquatic Science Spatial variability of macrozoobenthic diversity on tidal flats of the Niger Delta, Nigeria : the role of substratum Spatial variability of macrozoobenthic diversity on tidal flats of the Niger Delta , Nigeria : the rol," African J. Aquat. Sci., vol. 39, no. 1, pp. 37-41, 2014.

[7] K. Fauchald, The polychaete worms. Definitions and keys to the orders, families and genera. Los Angeles, 1977.

[8] B. Dharma, Recent \& fossil Indonesian shells. ConchBooks, 2005.

[9] S. J. Gale and P. G. Hoare, "Bulk sampling of coarse clastic sediments for particle-size analysis," Earth Surf.

Process. Landforms, vol. 17, no. 7, pp. 729-733, 1992.

[10] B. A. Schumacher, "Methods for the determination of total organic carbon (TOC) in soils and sediments," 2002.

[11] C. E. Shannon and W. Weaver, "The measurement theory of communication," Urbana Univ. Illinois Press, 1963.

[12] F. S. Prasetiya, "Effects of nutrient enrichment and shading on meiofauna with special emphasis on harpacticoid copepods in the Mediterranean seagrass beds," Vrije Universiteit Brussel, 2010.

[13] G. Janssen and S. Mulder, "Zonation of macrofauna across sandy beaches and surf zones along the Dutch coast," Oceanologia, vol. 47, no. 2, pp. 265-282, 2005.

[14] C. Van Colen, F. Montserrat, M. Vincx, P. M. J. Herman, T. Ysebaert, and S. Degraer, "Long-term divergent tidal flat benthic community recovery following hypoxia-induced mortality," Mar. Pollut. Bull., vol. 60, no. 2, pp. 178-186, 2010.

[15] C. Van Colen, F. Montserrat, M. Vincx, P. M. J. Herman, T. Ysebaert, and S. Degraer, "Macrobenthic recovery from hypoxia in an estuarine tidal mudflat," Mar. Ecol. Prog. Ser., vol. 372, pp. 3142, 2008.

[16] M. Basyuni et al., "Diversity and habitat characteristics of macrozoobenthos in the mangrove forest of Lubuk Kertang Village, North Sumatra, Indonesia," Biodiversitas, vol. 19, no. 1, pp. 311-317, 2018. 